\title{
College English Language Teaching Reform and EFL Lecturers' Teaching Practice: A Case Study in China
}

\author{
Sun Zhiyong*, Gurnam Kaur Sidhu, Priyadarshini Muthukrishnan \\ Faculty of Education, SEGI University Kota Damansara, Malaysia
}

Received June 29, 2019; Revised October 30, 2019; Accepted November 6, 2019

\begin{abstract}
Copyright $\mathrm{O} 2020$ by authors, all rights reserved. Authors agree that this article remains permanently open access under the terms of the Creative Commons Attribution License 4.0 International License
\end{abstract}

\begin{abstract}
The rapid expansion and development of newly-upgraded undergraduate colleges and universities across China witnessed a corresponding demand for the teaching and learning of English as Foreign Language (EFL). Accordingly, the Ministry of Education of China implemented the College English Language Teaching Reform (CELTR) to improve the teaching and learning of English language at higher institutions in China. The aim of this paper was to investigate EFL lecturers' perspectives of the CELTR and to what extent the CELTR had enhanced the EFL lecturers' teaching practice, which on converse influenced the effect and implementation of the CELTR. The study involved a total of 92 EFL lecturers from a newly-upgraded university located in Nanyang City in China. Data for the study were collected by using a questionnaire and semi-structured interviews with eight EFL lecturers adopting purposive sampling. The findings indicated that on the whole the EFL lecturers had moderate level of understanding and knowledge of the CELTR, and the lecturers' teaching practice had been satisfactorily enhanced due to the implementation of the CELTR. The college EFL lecturers considered and constantly adjusted their teaching contents, modes, methods and strategies to meet the students' specific needs better, and they tried to motivate the students' interests and participation in the EFL classroom teaching.
\end{abstract}

Keywords College English Language Teaching Reform, EFL Lecturer, Teaching Practice

\section{Introduction}

From the beginning of 21 st century, the popularization of education saw the fast development of tertiary education system all over the world especially across China. For example, there were only 573 undergraduate colleges and universities in the year of 1999, rapidly increased to 1219 by the end of 2015 [1], and this showed that nearly $53 \%$ of the colleges and universities were newly upgraded or constructed in China.

Tang [2] stated that the fast development of higher education also witnesses the increase in student enrolments in these colleges and universities, especially the newly upgraded or constructed ones. Accordingly, these higher institutions and students required a corresponding increase in university staff especially EFL lecturers, because of the open door policy practiced across China, English was fast becoming a foreign language in most institutions of higher learning, and there had been a great demand for EFL lecturers and the request for a variety of English language courses or programmes which demanded a relook at College English language programmes [3]. According to the Office of Improvement of Quality and Strategy, components and standards of teacher professional development (TPD) should be prepared in a way that, on the one hand, to enable lecturers to understand the various demands of college students in educational, emotional and social fields and on the other hand, indicate lecturers' qualifications in professional quality, knowledge, skills and attitudes and so on [4]. With the rapid development of higher education in China, the EFL lecturers are facing changing reform involving teaching ideas, devices, methods and modes, etc. As a public and basic course, college English language teaching is special for English language lecturers' professional knowledge and teaching abilities and so on [5].

This consequently led to the Ministry of Education of China implementing the Outlines of the National Medium and Long Term Educational Reform and Development Programme [6], which clearly pointed out that lecturers are the key elements to the success of Education Project. Quality education cannot be achieved without excellent lecturers, which indicates that the EFL lecturers must improve their teaching practice constantly to meet the new demands of the students for their better progress and 
development. Alongside this programme is the Guidelines on College English Language Teaching [7] that highlighted EFL lecturers' qualities, abilities and levels are the key factors which can help to improve teaching performance. In January, 2018, the State Council of China emphasizes that "Hundred years' policy based on education; while the education policy based on lecturers" once again [8]. All of these indicate that EFL lecturers must take steps and measures to improve their teaching practice.

Except for the requirements and challenges by the reform, there are opportunities with the guide and push of the CELTR. Khan and Begum [9] stated, given more opportunities for learning, knowledge and skills, lecturers' teaching practice will be improved. English is always being taught as a foreign language in China, the college EFL lecturers are encouraged to participate in TPD training programmes to learn and communicate thus to improve their teaching practices constantly [10]. The objectives of education and teaching cannot be achieved without EFL lecturers' teaching practice. Teaching practice is the precondition and foundation of education and teaching reform.

On the basis of this, the EFL lecturers must acquire the latest international ideas of education and teaching, knowledge of interdiscipline and abilities to introduce and spread English language and culture to promote college students' better progress and development to catch up with the time. And the improvement and development of the college EFL lecturers' professional qualities, abilities and levels need policy guarantee combing with the lecturers' self-pursuit and hard working together. Nevertheless, a large number of the EFL lecturers at newly-upgraded colleges or universities have some difficulties in conducting teaching practice to facilitate reform, especially in improving and enhancing teaching and learning under the implementation of CELTR [3]. On the other hand, Rui [10] stated that there really exist different types of setbacks and discrepancies in the process of English language teaching and EFL lecturers' professional development including heavy teaching loads, weak awareness of the lecturers' self-development, and so on. Therefore, it is critically important to note the importance of teaching practice and awareness regarding the degree of the professional development will help to recognize the lecturers' strengths and weaknesses to strengthen their strengths and overcome their weaknesses [11].

\section{The College English Language Teaching Reform in China}

In 2016, the Ministry of Education of China began to carry out the CELTR. The National Foreign Language Teaching Advisory Board drew up and issued The Guidelines to facilitate reform to improve College English language teaching standard and quality and so on.

In China, College English is a public and basic course for almost all the non-English major students in the first two years of their college or university education. The important teaching objectives of the CELTR are to develop college students' abilities of using English language including listening, speaking, reading, writing and translating, to enhance their awareness of intercultural communication and communicative competence, and to develop them into autonomous language learners capable of meeting the personal, social and national needs for development [7].

Under the CELTR, the college EFL lecturers are encouraged to shift from the traditional teaching mode of lecturer-centred to a popular mode of more student-centred approach. Therefore, EFL instructors are encouraged to relook and rethink about transforming their teaching activities from pure 'teaching' to more interactive and 'learning' perspective. In order to achieve teaching objectives, to improve the actual teaching effectiveness and quality, the college EFL lecturers and the college students need to take different ways and approaches, including lecturers' teaching methods, students' learning methods and the coordination and unification of them. Teaching methods pay attention to teaching styles and teaching activities, and pay more attention to learning styles and learning activities [12]. Tyler [13] emphasized that effective teaching must be centred on students' participation in classroom teaching and learning. Based on this, the supportive teacher-student relationship is important and necessary for teaching and learning to be cultivated and built. According to Roeser et al [14], the supportive teacher-student relationship and harmonious classroom climate can promote students' feelings of belonging in the classroom and thereby enhance their levels of participation and engagement in the EFL classroom, especially when students feel they are valued members in a learning community, they are positively involved in classroom activities, thus, they can learn more because of their greater engagement and on-task-behaviour. Furthermore, they will be less likely to be disruptive, oppositional or silently alienated, and therefore they will require fewer disciplinary referrals. Wang [12] stated that teaching means mainly refers to the tools, media and equipment for teaching and learning. With the rapid development of new internet techniques in the Internet time, computer network technologies have become the indispensable modern teaching means in English language teaching and learning. The main purpose of modern teaching means is to promote teaching and learning, and the most important is to assure the teaching effectiveness and quality, etc.

The Outlines [6] clearly stated that the main contents of TPD are to update and enrich lecturers' ideas, to promote their professional levels, to study teaching methods and approaches, and to improve teaching quality. The main 
approaches are to keep studying and taking part in teaching reform and research, etc.

With the implementation of the CELTR, English language lecturers are gradually realizing the value and significance of the changes in the teaching and learning approaches and modes in the EFL classrooms in China. However, since the implementation of the CELTR in China in 2016, there are no comprehensive studies that have explored the lecturers' teaching practice from the perspective of the CELTR [3]. Therefore the main aim of this paper is to investigate how the CELTR has enhanced the EFL lecturers' teaching practice in their EFL classrooms teaching.

\section{Teaching Practice}

Teaching practice is the precondition and foundation of education and teaching reform. English is always being taught as a foreign language in China, the college EFL lecturers are encouraged to participate in teacher professional development training programmes to learn and communicate thus to improve their teaching practice constantly [10].

There is one common idea which is popular in the world that the education reform and development must be carried out through lecturers' teaching activities [15]. Before 1970 s, teaching was viewed as behaviourism, and it was one kind of skill which could be achieved through training [16]. With the development of cognitive psychology, teaching was treated as the decision process of recognizing class information [17]. Generally, the research in China believes that teaching practice is such an activity in which lecturers guide students to grasp knowledge and skills through the media of teaching contents and materials. Simultaneously, lecturers build the relationship between themselves and the students [18].

Teaching practice is divided into two types. One is the generalized definition, which is believed the activity of teaching by lecturers and learning by students. The other is the activity of guiding students' learning by lecturers [15]. This study focuses on the influence and enhancement of the CELTR on EFL lecturers' classroom teaching. So the teaching practice under the current study refers to the classroom teaching which is mainly influenced by the factors of teaching ideas, professional knowledge, teaching abilities, language abilities and reflection abilities, and so on.

As performers and practitioners of teaching reform, college EFL lecturers must adjust their ideas and behaviours to meet the demands of teaching reform and students. And they must actively adapt to the new situation of the development of higher education; actively adapt to the new requirements of college English curriculum system; actively adapt to meet the needs of current college English language teaching better under the information environment, and to improve their professional knowledge, levels and teaching abilities continuously. In addition to mastering professional theories and knowledge, college EFL lecturers must possess the awareness of curriculum construction, the ability of selecting teaching contents, the ability of adjusting teaching methods and strategies, the consciousness of establishing students as the main body of English learning, the consciousness of teaching reform, the ability of modern educational technology application, etc. They should establish the idea of lifelong learning and realize the main contents of TPD including updating teaching ideas, enhancing their professional knowledge and qualities, researching teaching methods and improving the teaching performance, and they also should continue to actively participate in learning and teaching research and teaching reform [12].

As a matter of fact, the speed and degree of changing of English language lecturers' teaching ideas and behaviours influence and decide the process and result of teaching reform. The recognition system of the lecturers is based on how they understand the education values, teaching objectives, teaching contents and process, etc. The English language lecturers' ideas directly influence the effect of teaching reform and development. So, it is very important to improve the English language lecturers' qualities and levels in order to cultivate high-qualified students. For lecturers, they must acquire not only the professional knowledge and skills, but also the abilities of English language and cultural communication [10].

Therefore, the college EFL lecturers must update constantly their knowledge structure, adjust their skills and emotions, improve their abilities of analysing, discussing, evaluating and changing their teaching ideologies and modes and so on. As teaching practitioners, they need to conduct teaching research and take it as an important approach to improve professional accomplishment and development [10]. According to this, it is easy to come to the idea that EFL lecturers' improvement and development cannot be separated from teaching practice. Without teaching practice, lecturers cannot keep up with the changing teaching ideas and requirements and to meet the college students' specific demands in new time. So, teaching practice is a must for teaching reform and lecturers' further development.

\section{The Study}

The current study was conducted at a newly-upgraded university in Henan Province, Central China, which is located in the city of Nanyang. The case study involved a total of 92 EFL lecturers. Out of all the 92 lecturers, $89 \%$ were females and $11 \%$ were males. The data for the study were collected by using a mixed method approach involving both quantitative and qualitative instruments including a questionnaire and semi-structured interviews. 
The questionnaire was validated by a panel of experts and the pilot study findings revealed that the reliability of the questionnaire stood at $0.84-0.92$. Both these procedures indicated that the questionnaires were both reliable and valid.

In this study, semi-structured interviews were conducted in order to obtain more insights from respondents on the findings. Each interview varied in length and ranged between forty five minutes to one hour. This is important since it allows the respondents to provide more in-depth information, ideas and perceptions around the topic of the interview [19]. The interview comprised of four sections including fourteen specific questions. It began with simple and basic warm-up questions, such as "Could you introduce yourself?" and "How long have you been teaching the course? These warm up questions were aimed to keep the respondents at ease. Questions asked were also framed clearly so that they would not pose as a cognitive burden to the respondents. The second section investigated lecturers' perspectives of their understanding of CELTR and classroom teaching. The third section explored the respondents' ideas or opinions about teaching practice. The final section of the interview session required the respondents to provide their in-depth insights into planning for their teaching and professional development. Data collected through the interview analysis were used as secondary data to support and to triangulate the data gathered from the questionnaire. A semi-structured interview protocol was employed to obtain insights and deep understanding of the respondents' considerations and opinions about their teaching. All the interviews were conducted and recorded on a voice recorder and then transcribed for future analysis. Before conducting the interviews, the interview questions were first checked and validated by a panel of experts to judge whether the instruments were valid in accordance with the research theme [19]. The interview questions for the current study were given to two experts selected on their area of expertise, research experience and academic qualifications and so on. The panel of experts comprised a professor and an associate professor from the Department of Public Foreign Teaching at University WL. The panel of experts advocated that the items of interview questions were valid to investigate the research objectives. After conducting the interviews, each of the transcriptions of the interviews was taken back to each of the respondents to verify and validate their accuracy. This process known as member checking is a very significant way to validate qualitative data where respondents can show their agreement or disagreement on the data transcribed [19]. After the semi-structured interviews conducted with the respondents, the next process that followed was the coding of the data where they were grouped according to the themes based on the relevant topics of the study. This process was followed by breaking down some of the transcribed texts into categories of different levels including words, phrases and sentences.
The resulting descriptions and themes represented the findings through narratives where some of the interview data were used verbatim to highlight what were actually expressed by interviewees on the issues discussed at the same time making an interpretation of the meaning of the results by reflecting on the impact of the findings [19].

Furthermore, the qualitative data were collected via face-to-face interviews with eight respondents, who were a sub-set from the 92 EFL lecturers involved in this study. Keeping in line with ethics in research, the eight respondents were given pseudonyms and were referred to as Respondents $\mathrm{C} 1$ to $\mathrm{C} 8$. In this study, a code such as Respondent $\mathrm{C} 1 \mathrm{M}$ meant Candidate number 1 who is a male.

All the quantitative data were analysed using both descriptive and inferential statistics by employing the SPSS Version 20. The qualitative data were analyzed thematically to answer the research question posed in this study. Given below are the main findings of this study.

\section{Results and Discussion}

The main aspects analysed were the college EFL lecturers' perspectives of CELTR including their knowledge and understanding of the aim of CELTR and to what extent the CELTR had influenced lecturers' teaching practice. Here respondents were required to respond to different items based on a 5-point Likert scale ranging from $1=$ Strongly Disagree, $2=$ Disagree, $3=$ Neutral, $4=$ Agree, $5=$ Strongly Agree. The findings are presented in Table 1and Table 2.

Table 1. EFL Lecturers' Perspectives of the CELTR $(n=92)$

\begin{tabular}{|l|c|c|}
\hline \multicolumn{1}{|c|}{ Items } & Mean & SD \\
\hline $\begin{array}{l}\text { I read articles about reform on College English } \\
\text { language teaching to know the trend of College } \\
\text { English language teaching. }\end{array}$ & 3.54 & 0857 \\
\hline I understand clearly the key points of CELTR. & 3.29 & 0.734 \\
\hline $\begin{array}{l}\text { I constantly improve teaching ability to meet the } \\
\text { needs of CELTR. }\end{array}$ & 3.92 & 0.50 \\
\hline $\begin{array}{l}\text { I read some books about reform and theories of } \\
\text { college English language teaching. }\end{array}$ & 3.57 & 0.760 \\
\hline $\begin{array}{l}\text { I discuss my understanding about College English } \\
\text { language teaching with other lecturers. }\end{array}$ & 3.89 & 0.687 \\
\hline
\end{tabular}

Overall: mean $=3.64, \mathrm{SD}=0.523$

(Scale: $1=$ Strongly Disagree, $2=$ Disagree, $3=$ Neutral, 4=Agree, $5=$ Strongly Agree)

The findings in Table 1 show that on the whole EFL lecturers have moderate level of understanding and knowledge of the CELTR $(\mathrm{M}=3.64, \mathrm{SD}=0.523)$. They also took positive steps towards gaining a better understanding of CELTR as they were involved in reading books $(\mathrm{M}=3.57, \mathrm{SD}=0.760)$ and articles to gain an in-depth understanding of the reform. More importantly, they discussed and enhanced their understanding by discussing CELTR with their colleagues $(\mathrm{M}=3.89, \mathrm{SD}=0.687)$. On the 
other hand, their knowledge and understanding of the CELTR was at the moderate level as their understanding of key issues recorded a mean score of $3.29(\mathrm{SD}=0.734)$. Nevertheless, they were seen taking positive steps to enhance their practice in EFL teaching as they were actively involved in improving their teaching ability to meet the demands of the CELTR $(\mathrm{M}=3.92, \mathrm{SD}=0.650)$.

The above findings from the quantitative data were further corroborated with the qualitative findings obtained from the interviews conducted with the EFL lecturers. The interview session also explored the College EFL lecturers' perspectives of the CELTR including the aim of CELTR and EFL lecturers' roles under the College English language teaching.

One of the main aspects investigated was the EFL lecturers' understanding of the aim of the CELTR. On the whole, the respondents displayed moderate understanding of the aim and what changes it aspired to bring into the EFL classrooms. This is displayed in the excerpts from three respondents.

"Firstly, I must make the students understand the objectives of College English learning, hum. One of the most obvious and direct objectives is they must or have to pass CET-4 (College English Test Band 4 for college students after the first two years' English learning). " $(C 7 F)$

"For the College English teaching, I think the basic task is to cultivate the students' ability of listening, speaking, reading, writing and translating. During the process of learning language, they can learn culture knowledge and so on through the teaching contents and exercises." $(C 8 F)$

"My main task is to introduce the culture and the usage of new words, which is the language and knowledge in the textbook ... I introduce the language points and analyse the sentences to help them to understand. We should do more discussions about the College English teaching reform.."(C1M)

The main aim of the CELTR is to develop college students' ability in using English, especially the ability of listening and speaking, to enhance their intercultural communication awareness and competence, and to develop them into autonomous language learners who are capable of meeting the personal, social and national needs for development in the future [12].

According to the English language lecturers' statements, they understood the main aim of the CELTR. Thus, they could guide college students to learn College English with clear direction and purpose help them to finish teaching tasks and achieve the teaching objectives, which was more helpful for the students' better improvement and development.

Lecturers as instructors should focus on developing students' comprehensive levels and abilities in English language learning, and this includes improving the English language ability of students on listening, speaking, reading, writing and translating. Students need to develop each of these skills in English language learning, and as well as the application of these abilities in contexts. Some respondents stated that as English language was the foreign language to Chinese students, they needed to exercise more language outputs in order to practice, and this helped the students to master foreign language, and without frequent language outputs, it was very difficult for students to remember what they had learned. Below are some excerpts from two respondents.

"For the College English teaching...this is the common method. The final purpose is to cultivate the students' ability of applying, English language competence and to improve their consciousness of cross-culture communication." (C6F)

"I think the most important of College English language teaching is to improve the students' comprehensive levels and abilities, including listening, speaking, reading, writing and translating. As a lecturer, I should provide more learning methods and skills to help them to develop." (C5F)

Respondents stated that lecturers need to provide comprehensive guidance to students. The guidance should have more outputs such as motivating students to speak English in classes and read actual texts and English materials to help students to make progress and achievements in English language learning. Respondents also stated that lecturers need to effectively use intrinsic motivations to motivate student's efforts and interests in learning English language, this included praising students during the class and never diminishing the efforts of students, finding topics that students were interested in through fun-learning, and focusing more on students-based learning and activities. Gardner [20] stressed that motivation plays the important role to language learners; it is the desire to learn a language, the motivation intensity, and attitudes towards learning such language. On the other hand, lecturers need to supervise and guide students based on their current levels, and introduce different methods and skills in English language learning for students with different needs and levels. In return, criticizing has been viewed as the negative tool to be used by lecturers, and this showed that the scaffolding technique should be applied by lecturers, and based on students' language abilities and levels to determine the specific inputs that students required at their current levels to make improvements. Below are some excerpts of interviews and reflective journals from some respondents.

"I think we should motivate the students, and I think it is okay if the students can open their mouths to speak English. There is no high requirement; it is ok if the students would like to speak. I am afraid they do not speak, do no practice, even they do not read the texts. So, I often motivate the students, there are 
lower requirements, more motivation. If they practice, they make progress, and some achievements. I feel I had no whole understanding of this before." (C3F)

"During their learning, we should guide, supervise and urge to make them study better. I asked the students to preview the text, but only $10 \%$ of them do it. We should consider more about how to guide the students' learning. This is very important." $(C 2 F)$

"I give class to students. As I expected, they remember the event, but they do not know every detail of it. The information, however, we know, is very helpful for them to understand the text. Therefore, I take some time to make them get all about it. Some students who have previewed the text before class ask me some questions, and I give them answers and explanation. Sometimes there are no questions, I only point out some language points and give questions for them to think and answer." (C4F)

Respondents during the interviews also stated that lecturers should build good and harmonious relationship with students. The content relationship could help to attract students to be active in learning in classes. Besides, language learning is boredom, and teaching in interesting way will help to attract students' attention in classes and develop their interests in English learning. Indeed, motivation is important from lecturer as the source of energy given to students to develop their interests for foreign language learning and acquisitions.

The overall findings indicated that the EFL lecturers possessed rather concrete perceptions and understanding of College English Language Teaching. They viewed CELT as the process of cultivating and motivating students' interest to learn EFL. The guidance placed by the lecturers on students was important for the success of English language learning. From the interviews, the lecturers' observation on students helped to obtain their understandings towards the different levels and abilities of students, and this determined the efforts and guidance levels which the lecturers should give to each student, and as well as introducing suitable English language learning methods to students to effectively improve their results of learning.

According to Rui [10], for any new reform to be effective instructors need to have good understanding and positive attitudes. Under the guide of the CELTR, the EFL lecturers showed corresponding changes and the most important was to update their knowledge and understanding of the CELTR.

The overall mean score for the eight items is 4.02 $(\mathrm{SD}=0.455)$ which show that respondents felt that their teaching practice had been improved under the implementation of the CELTR. Among the eight items, the highest mean score is $4.26(\mathrm{SD}=0.709)$, which showed that the majority of the respondents strongly agreed that they adjusted their teaching objectives based on students' levels and demands. Besides that, large improvements in teaching practices under the CELTR has also discovered in the aspects of adjusting teaching methods or strategies based on students' needs $(\mathrm{M}=4.19, \mathrm{SD}=0.694)$, helping students to adjust learning strategies for their self-learning $(\mathrm{M}=4.15$, $\mathrm{SD}=0.694$ ), and reviewing overall teaching process after class to determine weakness and finding solutions to make improvements in the next lesson $(\mathrm{M}=4.02, \mathrm{SD}=0.695)$. However, the least teaching practice improvement under CELTR were discovered in the aspect of not actively take part in the practice of the reform of College English language teaching $(\mathrm{M}=3.76, \mathrm{SD}=0.856)$, but it is at the acceptable level of making improvement.

Table 2. Lecturers' Teaching Practice under the CELTR $(n=92)$

\begin{tabular}{|l|c|c|}
\hline \multicolumn{1}{|c|}{ Items } & Mean & SD \\
\hline $\begin{array}{l}\text { I motivate the students to take part in different } \\
\text { kinds of activities in classroom. }\end{array}$ & 3.99 & 0.687 \\
\hline $\begin{array}{l}\text { I adjust my teaching objectives according to } \\
\text { students' abilities, levels and demands. }\end{array}$ & 4.26 & 0.709 \\
\hline $\begin{array}{l}\text { I adjust my teaching methods or strategies } \\
\text { according to students' needs. }\end{array}$ & 4.19 & 0.694 \\
\hline $\begin{array}{l}\text { I have accumulated rich teaching experience } \\
\text { through teaching practice. }\end{array}$ & 3.82 & 0.755 \\
\hline $\begin{array}{l}\text { I actively take part in the practice of the reform of } \\
\text { College English language teaching. }\end{array}$ & 3.76 & 0.856 \\
\hline $\begin{array}{l}\text { I review the overall teaching process after class } \\
\text { and find out solutions to solve the problems in } \\
\text { teaching. }\end{array}$ & 4.02 & 0.695 \\
\hline $\begin{array}{l}\text { I am able to help students adjust their learning } \\
\text { strategies for students' self-learning. }\end{array}$ & 4.15 & 0.694 \\
\hline $\begin{array}{l}\text { I communicate with student in order to find out } \\
\text { the problems and shortcomings in teaching. }\end{array}$ & 3.99 & 0.749 \\
\hline
\end{tabular}

\section{Overall: mean $=4.02, \mathrm{SD}=0.455$}

(Scale: $1=$ Strongly Disagree, $2=$ Disagree, $3=$ Neutral, 4=Agree, $5=$ Strongly Agree)

The above findings from the quantitative data were further corroborated with the qualitative findings obtained from the interviews conducted with the English language lecturers. The interview session also explored the College EFL lecturers' teaching practice under the CELTR.

Rui [10] stated that, the EFL lecturers' knowledge and understanding of the CELTR can help to make their roles clearer and to improve their teaching and college students' learning and development. Facing the pressure and challenges under the implementation of the CELTR, the EFL lecturers gradually realized and found out that there were some problems in their teaching and the students' learning, and they began to take some positive steps and measures to change and solve the problems to improve their teaching practice constantly.

During the process of interviews with the EFL lecturers, most of the lecturers were rather serious and claimed they read in advance many materials about the CELTR. They stated their opinions and solutions to improve their teaching practice due to the implementation of the CELTR. The following are some excerpts from the interviews.

"There were still some problems after careful 
consideration. I came to realize that I just had a general outline for the teaching, but I had no specific plan or arrangement for the teaching. ... I did some adjustments to draw up the specific plans for the whole teaching, including classroom activities, oral presentations and the homework..." (C2F)

"It will be better if we teach according to the students' specific needs." (C1M)

After finding out the problems in his teaching process, Respondent $\mathrm{C} 1 \mathrm{M}$ produced some ideas and drew a conclusion and he stated

"Firstly, I should set up the idea of lifelong learning and deepen my professional knowledge and ability. Secondly, I should improve our professional and research ability to study the problems in teaching and teaching reform. Thirdly, I need constant reflections to make progress. Fourthly, I should communicate with the other lecturers, especially the excellent and experienced lecturers, and listen to the students' suggestions. By doing these, I can consider better to adjust and improve the teaching. Lastly, I should innovate our teaching...." (C1M)

Respondent $\mathrm{C} 2 \mathrm{~F}$ and $\mathrm{C} 3 \mathrm{~F}$ expressed similar opinions on how to improve teaching practices including adjusting teaching contents, teaching methods and changing the lecturers' roles and so on.

"And I think there are some problems which can be improved. For example, the design and arrangement of teaching activities and the teaching contents, including the interactions between me and the students." (C2F)

"I can change the teaching contents according to the students' needs. I can introduce new knowledge for the students which they are interested in. ... I need to make some changes ... to motivate the students' enthusiasm of learning English. ... So I want to make more efforts to motivate the students' cooperation with my teaching." $(\mathrm{C} 3 \mathrm{~F})$

And these opinions were also echoed and supported by another Respondent $\mathrm{C} 4 \mathrm{~F}$ and $\mathrm{C} 5 \mathrm{~F}$, who were quoted as saying

"As a lecturer, I should provide more learning methods and skills to help them to develop. I need to learn more to meet the students' needs to improve their development. The lecturer can add more new knowledge to the students to motivate their interest." (C4F)

"I think it will be better if the lecturers get together to discuss the problems in teaching to improve teaching. We can learn from each other. We can have lectures from other lecturers and draw a conclusion to promote our teaching practice." $(\mathrm{C} 5 \mathrm{~F})$

According to the EFL lecturers' statements, they realized some problems in their teaching and the students' learning, they took consideration and reflection carefully on how to improve their teaching practices, they made some changes and adjustments involving in teaching plans, teaching contents, teaching methods, teaching activities and interaction between them and the students to motivate and guide the students to learn English better, they considered that they must keep up with the time to study and understand the new CELTR, they needed to update teaching ideology, to improve teaching practices, to carry on their new roles and so on through reading some books and articles about reflective teaching, and how to apply them into their classroom teaching activities, which could help to adjust the teaching strategies, modes and contents to meet the students' specific needs better. And they believed that the more important was that they must change their traditional roles and adopt the new teaching mode of student-centred approach which was proposed and advocated by the CELTR.

These findings corroborate with the view held by Wang [12] who stated that EFL lecturers must take active measures to adapt to the new situation and requirements of the development of higher education to conduct flexible teaching to meet students' demands better.

On the other hand, the Guidelines on College English Language Teaching by the Ministry of Education of China [7] pointed out that the College EFL lecturers and the college students need to take different ways and approaches in order to achieve teaching objective, to improve the actual teaching effectiveness and quality. Wang [12] stated that teaching methods should not only pay attention to lecturers' teaching styles and teaching activities, but also pay more attention to students' learning styles and learning activities. When students feel they are valued members in a learning community, they are positively involved in classroom teaching activities, thus, they can learn more because of their greater participation. The teaching student-centred mode can promote students' feelings of belonging in the classroom and thereby enhance their levels of engagement in the classroom [18]. Most importantly, the principal purpose of the CELTR and the enhancement is for students' progress and development.

\section{Conclusions}

On the whole, this case study revealed that the EFL lecturers had moderate level of understanding of the CELTR in improvement in their teaching abilities to meet the CELTR standards and requirements, discussing with other lecturers for sharing their teaching experiences that sought improvements from other lecturers, and reading books and articles about reform on College English language teaching in order to possess understanding for the trend of College English language teaching and learning. Nevertheless, some EFL lecturers' low level of 
perspectives of the CELTR indicate that they did not clearly understand the principles and key points of the CELTR, and this maybe the potential issues in which it could trigger their teaching efficiencies under the CELTR. Also the EFL lecturers' teaching practice had witnessed some improvement and this could probably be due to the implementation of the CELTR. The findings showed that during the process of implementation of the CELTR, the college EFL lecturers constantly adjusted their teaching plans, contents, modes, methods and strategies to meet the students' specific needs better, and they tried to motivate the students' interests and participation in the teaching activities, which was obviously helpful in their smooth development of teaching and for the improvement of teaching practice.

On the other hand, the EFL lecturers deeply realized the importance and value of interactions and communication between them and the students, so they made much effort to provide more opportunities for student-centred learning which had been postulated under the CELTR. The lecturers claimed their students were provided the opportunities to be involved in active listening and speaking activities to improve their abilities of using English and so on. All these bear testimony that the implementation of the CELTR has to a certain extent enhanced lecturers' teaching practice.

Finally, it is important to note that due to the limited sample size that involved only a few samples from one university, the findings of this study cannot be generalized on the total population of students in other universities in China. Nevertheless, the study has shed some light on the effect of the CELTR on lecturers' teaching practice. It is hoped that the findings of this study will spur research in more universities on the effects of the implementation of the CELTR.

\section{REFERENCES}

[1] H. Z. Xie, Educational Statistics Yearbook of China. Beijing: China Statistics Press, 2016.

[2] X. Q. Tang, "Promoting EFL lecturers' professional development through reflective teaching," unpublished.

[3] Z. Y. Sun, G. K. Sidhu and M. Priyadrashini, "Lecturers' perspectives of the college English language teaching reform in China: A case study". The Turkish Online Journal of Design, Art and Communication, Sept 2018 Special Edition, pp. 1463-1469.

[4] S. Laei, "Teachers' development in educational system". Procedia-Social and Behavioral Sciences, 2012, 47, pp. 250-255.

[5] S. R. Wang, "Strengthening the construction of teaching staff, improving teachers' teaching ability". Foreign Language World, 2010, pp. 9-10.

[6] Outlines of the national medium and long term educational reform and development program. Beijing: Ministry of Education of the People's Republic of China, 2010.

[7] Guidelines on College English language teaching by the ministry of education of China. Beijing: Ministry of Education of the People's Republic of China, 2016.

[8] Suggestions on deepening the construction and reform of teaching staff. Beijing: Ministry of Education of the People's Republic of China, 2018.

[9] B. Khan, and S. Begum, "A professional development and learning tool for teachers". International Journal of Social Science and Education, 2012, 2(2), pp. 363-377.

[10] Y. P. Rui, An empirical study on English teachers' professional development. Beijing: National Defense Industry Press, 2011.

[11] F. Ayyoobi, H. Pourshafe, and A. Asgari, "Codification and validation of professional development questionnaire of teachers". International Education Studies, 2016, 9(4), pp. 215-224.

[12] S. R. Wang, "Explanation of key issues of guidelines on college English language teaching". Foreign Language World, 2016, 173(3): pp. 2-10.

[13] R. W. Tyler, The basic principles of pedagogy and teaching. Beijing: China Light Industry Press, 2014.

[14] R. W. Roeser, E. Skinner, J. Beer, and P. A. Jennings, "Mindfulness training and teachers' professional development: an emerging area of research and practice". Child Development Perspectives, 2012, 6, pp. 167-173.

[15] Y. Chen, "A study on novice English teachers professional development in colleges based on reflective teaching theory", unpublished.

[16] J. Robert, Language teacher education. London: Arnold, 1998.

[17] D. Woods, Teacher cognition in language teaching: Beliefs, decision-making and classroom practice. Cambridge: Cambridge University Press, 1996.

[18] Q. Q. Zhong, “Teaching practice and teacher professional development”. Global Education, 2007, 10, pp. 8-14.

[19] J. W. Creswell, Education research: Planning, conducting, and evaluating quantitative and qualitative research (4th ed.). London: Pearson, 2012.

[20] P. Gardner, "Language learning motivation: the student, the teacher, and the researcher". Texas Papers in Foreign Language Education, 2001, 6(1), PP. 1-18. 